\title{
A Parameter Based Heart Disease Detection Technique using Mining Technique
}

\author{
P.Sambasiva Rao ${ }^{1}$ and Dr. T.Uma Devi ${ }^{2}$
}

\begin{abstract}
With the recent outbound spread of chronicle heart diseases across the world, irrespective of gender and age, the medical practitioners are focusing on preventive measures rather than curing methods. Thus the modern research trends are bound to provide the preventive extension to the medical science. Although the medical practices can generate gigantic amount of relevant data pertaining to the diseases, however the medical science fail to deploy any technique to mine the data for predictive models. Thus the data mining and predictive models are the most suitable way to provide the necessary tools for predictive analysis. The work deploys a novel principle attribute analysis to understand the orientation of the attributes affecting the results. The work is based on UCI database and implements a novel approach to extract the parameters influencing disease detection. The final outcome of this work is to generate the most influencing heart Disease detecting parameters.
\end{abstract}

Keywords - HMM, Rule Based Approach, Genetic Algorithm for Search, Optimal Feature Selection

\section{INTRODUCTION}

The heart or the cardiovascular diseases have a huge impact on the death rates in the world especially in the developing countries. Celtia et al in the year of 2000 have proven that cardiovascular diseases cause $25 \%$ of the deaths. The work presented by World Bank Country groups in the year of 2001, had cited the health rate by heart diseases around $25 \%$. However the work of Mathers et al presented in the year of 2004 , had analysed the death rate as $46 \%$, which is a notable increase in the span of 4 years. It is predicted that in the year of 2020 an approximated 2.5 million people from India are likely to be severely affected by heart diseases. In spite of the best clinical practices and available medications, the death rates are increasing and expected to be $55 \%$ in India by the end of 2020 .

The focus of this work is to demonstrate a Novel Multilayer Perceptron Model to Detect Heart Disease Severity and motivated by the work of Asha Gowda et al. [1].

Also this work analyses the recent research outcomes from the parallel works. The present research trends are directing towards a more specific and focused study of predictive models for determining the severity of the heart diseases based on the clinical results and best possible computing techniques in Data Mining [2][3][4][5][6].

The outcomes from work of Huyan Wang at al had proposed a traditional model for Chinese medical practitioners based on a computing model to diagnosis based on the Bayesian model.

Also the works been carried out with the perspective of generic algorithm in order to produce expert systems are notable for prediction and diagnosis of heart diseases [7]. The work of Assanelli et al in the year of 1993 demonstrates the use of ECG data to predict the heart diseases. Meanwhile, $\mathrm{G}$. $\mathrm{Ng}$ et al has developed a chest pain expert system, which diagnoses the cause of chest pain leading towards the cardiac attacks.

Text classification techniques combined with a Naive Bayes classifier and relational learning algorithms are methods explained by Jennifer G et al [8] in the year of 1999. Hidden Markov Models are used in Craven in the year of 2001, but similar work to Rosario and Hearst was produced in the year of 2004, the research focus was entity recognition. A context based approach using MeSH term

\footnotetext{
${ }^{1}$ GITAM University, Visakhapatnam- 530045

${ }^{2}$ GITAM University, Visakhapatnam - 530045
} 
co-occurrences are used by Srinivasan and Rindflesch for relationship discrimination between diseases and drugs. A lot of work is focused on building rules used to extract relation. Feldman et al. used a rule-based system to extract relations that are focused on genes, proteins, drugs, and diseases and demonstrated in 2002. Friedman et al. go deeper into building a rule-based system by handcrafting a semantic grammar and a set of semantic constraints in order to recognize a range of biological and molecular relations.

In biomedical literature, rule-based approaches have been widely used for solving relation extraction tasks. The main sources of information used by this technique are either syntactic: part-ofspeech (POS) and syntactic structures; or semantic information in the form of fixed patterns that contain words that trigger a certain relation. One of the drawbacks of using methods based on rules is that they tend to require more human-expert effort than data-driven methods. The best rule-based systems are the ones that use rules constructed manually or semi automatically-extracted automatically and refined manually. A positive aspect of rule-based systems is the fact that they obtain good precision results, while the recall levels tend to be low. Syntactic rule-based relation extraction systems are complex systems based on additional tools used to assign POS tags or to extract syntactic parse trees. It is known that in the biomedical literature such tools are not yet at the state-of-the-art level as they are for general English texts, and therefore their performance on sentences is not always the best.

Henceforth this work can be visualized as the potential findings of work and guidelines for the performance of a framework that is capable to find relevant information about diseases and treatments in a medical domain repository. The results that obtained will show that it is a realistic scenario to use NLP and ML techniques to build a tool that capable to identify and disseminate textual information related to diseases and treatments.

Thus this work identifies the problems in the existing and parallel research outcomes as:

- Firstly, a lot of data pertaining to cardiac Disease are available, but the datasets are over populated with multiple parameters. The outcome of processing multiple parameters leads to high computational complexity and processing less parameter may lead to lower order of accuracy in prediction. Hence, there is a clear demand for a technique to identify most appropriate set of parameters to be processed during predictive analysis [9] [10] [11] [12] [13] [14].

- Secondly, there are various computation techniques deployed to timely predict with less computational complexity. However, the neural network based programming approaches are proven to be time efficient. Henceforth, there is also a demand for finding the optimal neural network setup for predictive analysis [15] [16] [17] [18].

\section{Proposed Framework for Pre-Processing}

The first step of this proposed work is the pre-processing framework for determining and extracting the influential parameters. The most appropriate algorithm for feature or attribute selection is a Genetic algorithm [1] [7], where initially all the attributes are considered as individual subsets and the final combination of the attributes or features are noted as optimal best feature subset. The framework is been proposed here:

Step-1. Calculate and Collect the list of attributes to be ordered in terms of significance:

$$
M[] \leftarrow \forall P \exists\left(\sum_{i=1}^{n} p_{i}\right)
$$

Where, $\mathrm{M}$ denotes the initial set of attributes, $\mathrm{P}$ denotes the total available list of attributes.

Step-2. Assign the selection vector as $\mathrm{S}[\mathrm{L}]$ where $\mathrm{L}$ is the size of the initial attribute list. Initially the vector is filled with zeros to denote no optimal subset is selected.

$$
\forall \mathrm{S}, \mathrm{S}[\mathrm{i}] \leftarrow 0
$$


Step-3. In this step of the algorithm, the fitness for all the attributes is been calculated so that the ranking can be provided for the features against all other attributes.

$$
\begin{aligned}
& { }_{\text {Info }}^{{ }_{\text {Gain }}}\left(S_{i}\right)= \\
& \left\{\begin{array}{l}
1+{ }_{\text {Info }} \text { Gain } \\
\text { if Info }_{\text {Gain }}\left(\text { Class }_{i}, S_{i}\right), \\
\left.1_{i}, S_{i}\right) \geq \text { Info }_{\text {Gain }} \\
{ }_{\text {Gain }}\left(\text { Class }_{i}, S_{i}\right), \text { Else }
\end{array}\right.
\end{aligned}
$$

Step-4. Once the attributes are been ranked, the final selected subset is produced.

$$
S[m] \leftarrow \text { Highest }\left(\operatorname{Info}_{\text {Gain }}(M)\right)
$$

The work analyses the data set provided by UCI machine learning [19]. Each database has the same instance format. While the databases have 76 raw attributes. The descriptions of the dataset

\begin{tabular}{|c|c|c|}
\hline $\begin{array}{l}\text { Serial } \\
\text { Number }\end{array}$ & $\begin{array}{l}\text { Parameter } \\
\text { Names }\end{array}$ & Parameter Descriptions \\
\hline 1 & ID & Patient identification number \\
\hline 2 & $\mathrm{CCF}$ & $\begin{array}{l}\text { Social security number (I replaced this with a dummy value of } \\
0 \text { ) }\end{array}$ \\
\hline 3 & $\mathrm{AGE}$ & Age in years \\
\hline 4 & SEX & Sex $(1=$ male; $0=$ female $)$ \\
\hline 5 & PAINLOC & Chest pain location $(1=$ substernal; $0=$ otherwise $)$ \\
\hline 6 & PAINEXER & $(1=$ provoked by exertion; $0=$ otherwise $)$ \\
\hline 7 & RELREST & $(1=$ relieved after rest; $0=$ otherwise $)$ \\
\hline 8 & PNCADEN & (Sum of 5,6, and 7$)$ \\
\hline 9 & $\mathrm{CP}$ & $\begin{array}{l}\text { Chest pain type } \\
\text {-- Value } 1 \text { typical angina } \\
\text {-- Value } 2 \text { atypical angina } \\
\text {-- Value } 3 \text { non-anginal pain } \\
\text {-- Value } 4 \text { asymptomatic }\end{array}$ \\
\hline 10 & TRESTBPS & Resting blood pressure (in $\mathrm{mm} \mathrm{Hg}$ on admission to the hospital \\
\hline 11 & HTN & Not Defined \\
\hline 12 & CHOL & Serum cholestoral in $\mathrm{mg} / \mathrm{dl}$ \\
\hline 13 & SMOKE & I believe this is $1=$ yes; $0=$ no (is or is not a smoker) \\
\hline 14 & CIGS & (Cigarettes per day) \\
\hline 15 & YEARS & (Number of years as a smoker) \\
\hline 16 & FBS & $($ Fasting blood sugar $>120 \mathrm{mg} / \mathrm{dl}) \quad(1=$ true; $0=$ false $)$ \\
\hline 17 & $\mathrm{DM}$ & $(1=$ history of diabetes; $0=$ no such history $)$ \\
\hline 18 & FAMHIST & Family history of coronary artery disease $(1=$ yes; $0=$ no $)$ \\
\hline 19 & RESTECG & $\begin{array}{l}\text { Resting electrocardiographic results } \\
\text {-- Value } 0 \text { normal } \\
\text {-- Value } 1 \text { having ST-T wave abnormality ( } \mathrm{T} \text { wave } \\
\text { inversions and/or ST } \\
\text { elevation or depression of }>0.05 \mathrm{mv} \text { ) } \\
\text {-- Value } 2 \text { showing probable or definite left ventricular } \\
\text { hypertrophy } \\
\text { by Estes' criteria }\end{array}$ \\
\hline
\end{tabular}
parameters are provided here [Table -1$]$ :

TABLE I: UCI HEART DISEASE DATABASES 


\begin{tabular}{|c|c|c|}
\hline 20 & EKGMO & (month of exercise ECG reading) \\
\hline 21 & EKGDAY & (day of exercise ECG reading) \\
\hline 22 & EKGYR & (year of exercise ECG reading) \\
\hline 23 & DIG & (digitalis used furing exercise ECG $1=$ yes; $0=$ no) \\
\hline 24 & PROP & (Beta blocker used during exercise ECG $1=$ yes; $0=$ no) \\
\hline 25 & NITR & (nitrates used during exercise ECG $1=$ yes; $0=$ no) \\
\hline 26 & PRO & $\begin{array}{l}\text { (calcium channel blocker used during exercise ECG } 1=\text { yes; } \\
0=\text { no) }\end{array}$ \\
\hline 27 & DIURETIC & (diuretic used used during exercise ECG $1=$ yes; $0=$ no) \\
\hline 28 & PROTO & $\begin{array}{l}\text { Exercise protocol } \\
\qquad \begin{aligned} 1 & =\text { Bruce } \\
2 & =\text { Kottus } \\
3 & =\text { mchenry } \\
4 & =\text { fast Balke } \\
5 & =\text { Balke } \\
6 & =\text { Noughton } \\
7 & =\text { bike } 150 \mathrm{kpa} \mathrm{min} / \mathrm{min} \\
8 & =\text { bike } 125 \mathrm{kpa} \mathrm{min} / \mathrm{min} \\
9 & =\text { bike } 100 \mathrm{kpa} \mathrm{min} / \mathrm{min} \\
10 & =\text { bike } 75 \mathrm{kpa} \mathrm{min} / \mathrm{min} \\
11 & =\text { bike } 50 \mathrm{kpa} \mathrm{min} / \mathrm{min} \\
12 & =\text { arm ergometer }\end{aligned}\end{array}$ \\
\hline 29 & THALDUR & Duration of exercise test in minutes \\
\hline 30 & THALTIME & Time when ST measure depression was noted \\
\hline 31 & MET & Mets achieved \\
\hline 32 & THALACH & Maximum heart rate achieved \\
\hline 33 & THALREST & Resting heart rate \\
\hline 34 & TPEAKBPS & Peak exercise blood pressure (first of 2 parts) \\
\hline 35 & PEAKBPD & Peak exercise blood pressure (second of 2 parts) \\
\hline 36 & DUMMY & \\
\hline 37 & TRESTBPD & Resting blood pressure \\
\hline 38 & EXANG & Exercise induced angina $(1=$ yes; $0=$ no $)$ \\
\hline 39 & XHYPO & $(1=$ yes; $0=$ no $)$ \\
\hline 40 & OLDPEAK & ST depression induced by exercise relative to rest \\
\hline 41 & SLOPE & $\begin{array}{l}\text { The slope of the peak exercise ST segment } \\
\text {-- Value } 1 \text { upsloping } \\
\text {-- Value } 2 \text { flat } \\
\text {-- Value } 3 \text { downsloping }\end{array}$ \\
\hline 42 & RLDV5 & Height at rest \\
\hline 43 & RLDV5E & Height at peak exercise \\
\hline 44 & $\mathrm{CA}$ & Number of major vessels (0-3) colored by flourosopy \\
\hline 45 & RESTCKM & Irrelevant \\
\hline 46 & EXERCKM & Irrelevant \\
\hline 47 & RESTEF & Rest raidonuclid Ejection fraction \\
\hline 48 & RESTWM & $\begin{array}{l}\text { Rest wall Motion abnormality } \\
\qquad \begin{aligned} 0 & =\text { none } \\
1 & =\text { mild or moderate } \\
2 & =\text { moderate or severe } \\
3 & =\text { akinesis or dyskmem }\end{aligned}\end{array}$ \\
\hline 49 & EXEREF & Exercise radinalid Ejection fraction \\
\hline 50 & EXERWM & Exercise wall Motion \\
\hline
\end{tabular}




\begin{tabular}{|c|c|c|}
\hline 51 & THAL & $3=$ normal; $6=$ fixed defect; $7=$ reversable defect \\
\hline 52 & THALSEV & Not used \\
\hline 53 & THALPUL & Not used \\
\hline 54 & EARLOBE & Not used \\
\hline 55 & $\mathrm{CMO}$ & Month of cardiac cath (perhaps "call") \\
\hline 56 & CDAY & Day of cardiac cath \\
\hline 57 & CYR & Year of cardiac cath \\
\hline 58 & NUM & $\begin{array}{l}\text { Diagnosis of heart disease (angiographic disease status) } \\
\text {-- Value } 0<50 \% \text { diameter narrowing } \\
\text {-- Value } 1>50 \% \text { diameter narrowing } \\
\text { (in any major vessel attributes } 59 \text { through } 68 \text { are vessels) }\end{array}$ \\
\hline 59 & LMT & Not Defined \\
\hline 60 & LADPROX & Not Defined \\
\hline 61 & LADDIST & Not Defined \\
\hline 62 & DIAG & Not Defined \\
\hline 63 & CXMAIN & Not Defined \\
\hline 64 & RAMUS & Not Defined \\
\hline 65 & OM1 & Not Defined \\
\hline 66 & OM2 & Not Defined \\
\hline 67 & RCAPROX & Not Defined \\
\hline 68 & RCADIST & Not Defined \\
\hline 69 & LVX1 & Not used \\
\hline 70 & LVX2 & Not used \\
\hline 71 & LVX3 & Not used \\
\hline 72 & LVX4 & Not used \\
\hline 73 & LVF & Not used \\
\hline 74 & CATHEF & Not used \\
\hline 75 & JUNK & Not used \\
\hline 76 & NAME & Last name of patient \\
\hline
\end{tabular}

Henceforth, the proposed framework constructs a correlation matrix to rank the attributes most likely to influence the results. Bayes net structure is presented here [Table - 2]:

TABLE II: Bayes Net Structure

\begin{tabular}{|l|l|l|}
\hline MERIT & $\begin{array}{l}\text { SCALE } \\
\text { D }\end{array}$ & Parameter Subsets \\
\hline 0.61438 & 0.80802 & $\begin{array}{l}471314192224252627293031323639404142444853555759 \\
606163656668707273\end{array}$ \\
\hline 0.56553 & 0.59578 & $\begin{array}{l}24567111319272930313240414344454849515254555759 \\
606162636465666770717273\end{array}$ \\
\hline 0.61334 & 0.80347 & $\begin{array}{l}471314171922242526272930313236394041424448535557 \\
59606163656668707273\end{array}$ \\
\hline 0.57217 & 0.62464 & $\begin{array}{l}471314151920222425262729303132363940414244485355 \\
57596061636668707273\end{array}$ \\
\hline 0.54682 & 0.51454 & $\begin{array}{l}26789111420222425262729303336383940414243444851 \\
535960626364656768707273\end{array}$ \\
\hline 0.55164 & 0.53548 & $\begin{array}{l}24579111317192729303132394041424447515354555759 \\
606163656668707273\end{array}$ \\
\hline 0.57864 & 0.65273 & $\begin{array}{l}471314192224252627303132363940414344454849515254 \\
5557596061626364656667707273\end{array}$ \\
\hline 0.42837 & 0 & $\begin{array}{l}23567111213181922232930313240414344454851555759 \\
61626364656769707273\end{array}$ \\
\hline
\end{tabular}




\begin{tabular}{|l|l|l|}
\hline 0.46084 & 0.14101 & $\begin{array}{l}47912131419202224252627293031323639404142445355 \\
565759606163656668707273\end{array}$ \\
\hline 0.58916 & 0.69843 & $\begin{array}{l}24567111319212227293031323940414344454855575960 \\
62636465677072\end{array}$ \\
\hline 0.60163 & 0.75263 & $\begin{array}{l}245711131922272930313239404143444548555759606263 \\
646567707273\end{array}$ \\
\hline 0.60201 & 0.75429 & $\begin{array}{l}245711131922272930313239404144455557596062636465 \\
67707273\end{array}$ \\
\hline 0.55207 & 0.53733 & $\begin{array}{l}236711131819222329303132404144454851555759616263 \\
646567697072\end{array}$ \\
\hline 0.56235 & 0.58199 & $\begin{array}{l}471314192224252627293031323639404142444748515253 \\
54555759606163656668707273\end{array}$ \\
\hline 0.5808 & 0.66213 & $\begin{array}{l}41314192224252627293031323639404142444853555760 \\
61636668707273\end{array}$ \\
\hline 0.6035 & 0.76075 & $\begin{array}{l}25711131922272930313238394041434445485557596062 \\
636465677072\end{array}$ \\
\hline 0.47965 & 0.22275 & $\begin{array}{l}245711131921222729303132343940414344454855575960 \\
6263646567707273\end{array}$ \\
\hline 0.56274 & 0.58368 & $\begin{array}{l}245711131927293031323940414344454849515254555759 \\
6061626364656667707273\end{array}$ \\
\hline 0.44954 & 0.09193 & $\begin{array}{l}471213141922242526272930313235363739404142444853 \\
5557596062636467707276\end{array}$ \\
\hline
\end{tabular}

Thus, finally the list of most appropriate attributes influencing the Disease is been listed here [Table - 3]:

TABLE III: ATTRIBUTES INFLUENCING THE DISEASE

\begin{tabular}{|c|c|}
\hline Serial Number & Parameter Names \\
\hline 4 & SEX \\
\hline 7 & RELREST \\
\hline 12 & CHOL \\
\hline 13 & SMOKE \\
\hline 14 & CIGS \\
\hline 19 & RESTECG \\
\hline 22 & EKGYR \\
\hline 24 & PROP \\
\hline 25 & NITR \\
\hline 26 & PRO \\
\hline 27 & DIURETIC \\
\hline 29 & THALDUR \\
\hline 30 & THALTIME \\
\hline 31 & MET \\
\hline 32 & THALACH \\
\hline 36 & DUMMY \\
\hline 39 & XHYPO \\
\hline 40 & OLDPEAK \\
\hline 41 & SLOPE \\
\hline 42 & RLDV5 \\
\hline 44 & CA \\
\hline 48 & RESTWM \\
\hline 53 & THALPUL \\
\hline
\end{tabular}




\begin{tabular}{|c|c|}
\hline 55 & CMO \\
\hline 57 & CYR \\
\hline 59 & LMT \\
\hline 60 & LADPROX \\
\hline 61 & LADDIST \\
\hline 63 & CXMAIN \\
\hline 65 & OM1 \\
\hline 66 & OM2 \\
\hline 67 & RCAPROX \\
\hline 68 & RCADIST \\
\hline 70 & LVX2 \\
\hline 72 & LVX4 \\
\hline 73 & LVF \\
\hline
\end{tabular}

As this work is intended to predict the heart Disease severity, hence the following parameters are also been included with the consideration of redundant attributes. Henceforth the optimal set of attributes for further analysis is listed.

\section{RESULTS AND DISCUSSION}

The objective of this work is to increase the accurately identify and cluster the dataset motivated by Volfer Rotz et al. [20] for multiple levels of Disease severity. Thus firstly, the categories of the severity are identified [Table -4$]$.

TABLE IV: CLUSTERS INFORMATION

\begin{tabular}{|c|c|}
\hline Disease Severity & Cluster Name \\
\hline No Disease & 0 \\
\hline Disease - 1 Major Blood Vessel Blocked & 1 \\
\hline Disease - 2 Major Blood Vessels Blocked & 2 \\
\hline Disease - 3 Major Blood Vessels Blocked & 3 \\
\hline Disease - 4 Major Blood Vessels Blocked & 4 \\
\hline
\end{tabular}

After the analysis of the dataset, the following clustering results are been obtained [Table -5$]$ :

TABLE V: SEVERITY BASED CLUSTERING

\begin{tabular}{|c|c|c|c|c|c|}
\hline Cluster Names & $\mathbf{0}$ & $\mathbf{1}$ & $\mathbf{2}$ & $\mathbf{3}$ & $\mathbf{4}$ \\
\hline $\mathbf{0}$ & 170 & 12 & 1 & 0 & 0 \\
\hline $\mathbf{1}$ & 18 & 8 & 2 & 0 & 0 \\
\hline $\mathbf{2}$ & 4 & 8 & 2 & 0 & 0 \\
\hline $\mathbf{3}$ & 0 & 9 & 1 & 7 & 1 \\
\hline $\mathbf{4}$ & 1 & 3 & 0 & 2 & 8 \\
\hline
\end{tabular}

Henceforth, this work analyses the effect of selected parameters over heart Disease severity detection influences.

In the analysis this work demonstrates the appropriate distribution over nominal parameter with Time [Figure - 1]. 


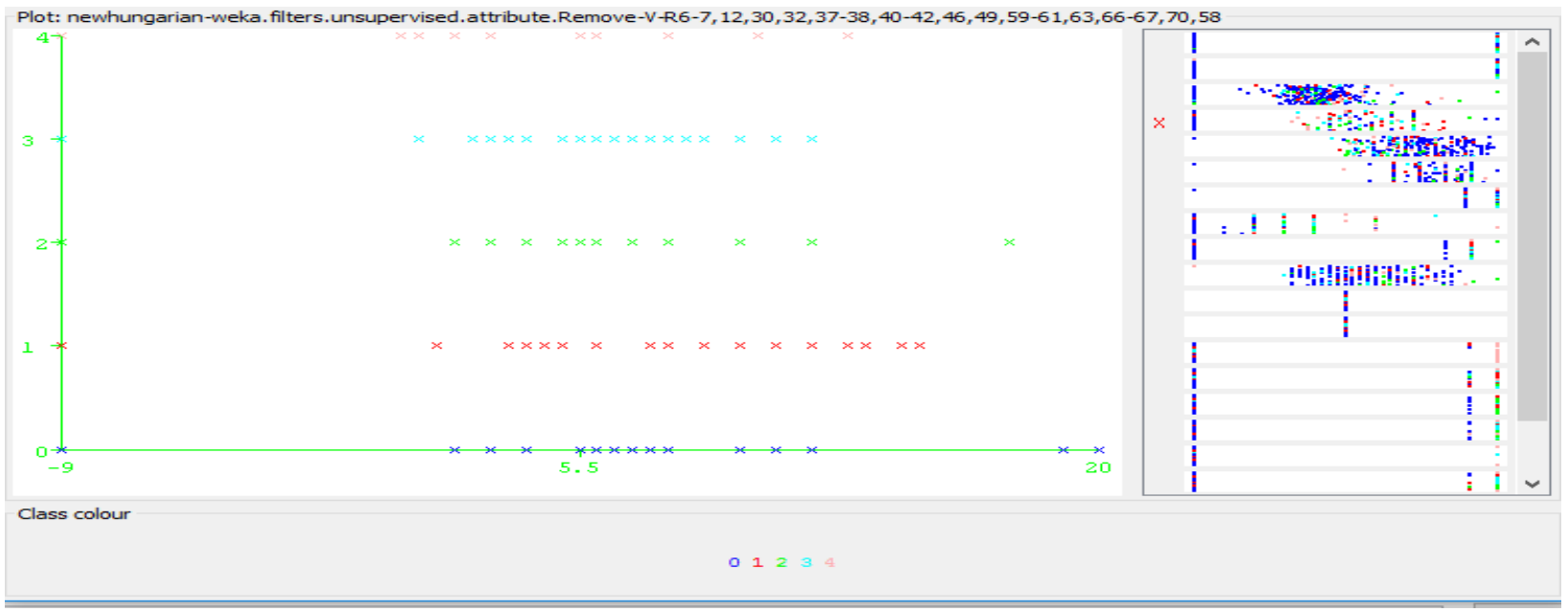

Figure 1: Time When St Measure Depression Was Noted for Selected Parameter after Reduction In the analysis this work demonstrates the appropriate distribution over nominal parameter with maximum heart rate achieved [Figure - 2].

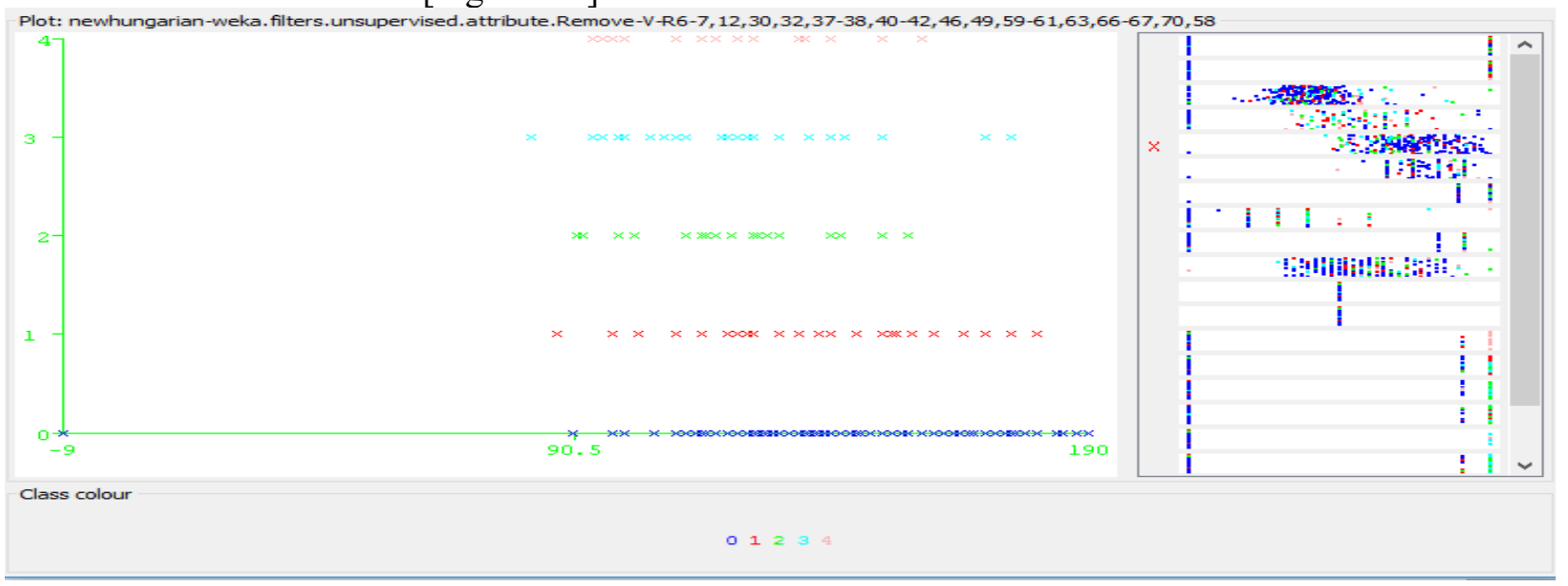

Figure 2: Maximum Heart Rate Achieved for Selected Parameter after Reduction

In the analysis this work demonstrates the appropriate distribution over nominal parameter with resting blood pressure [Figure - 3].

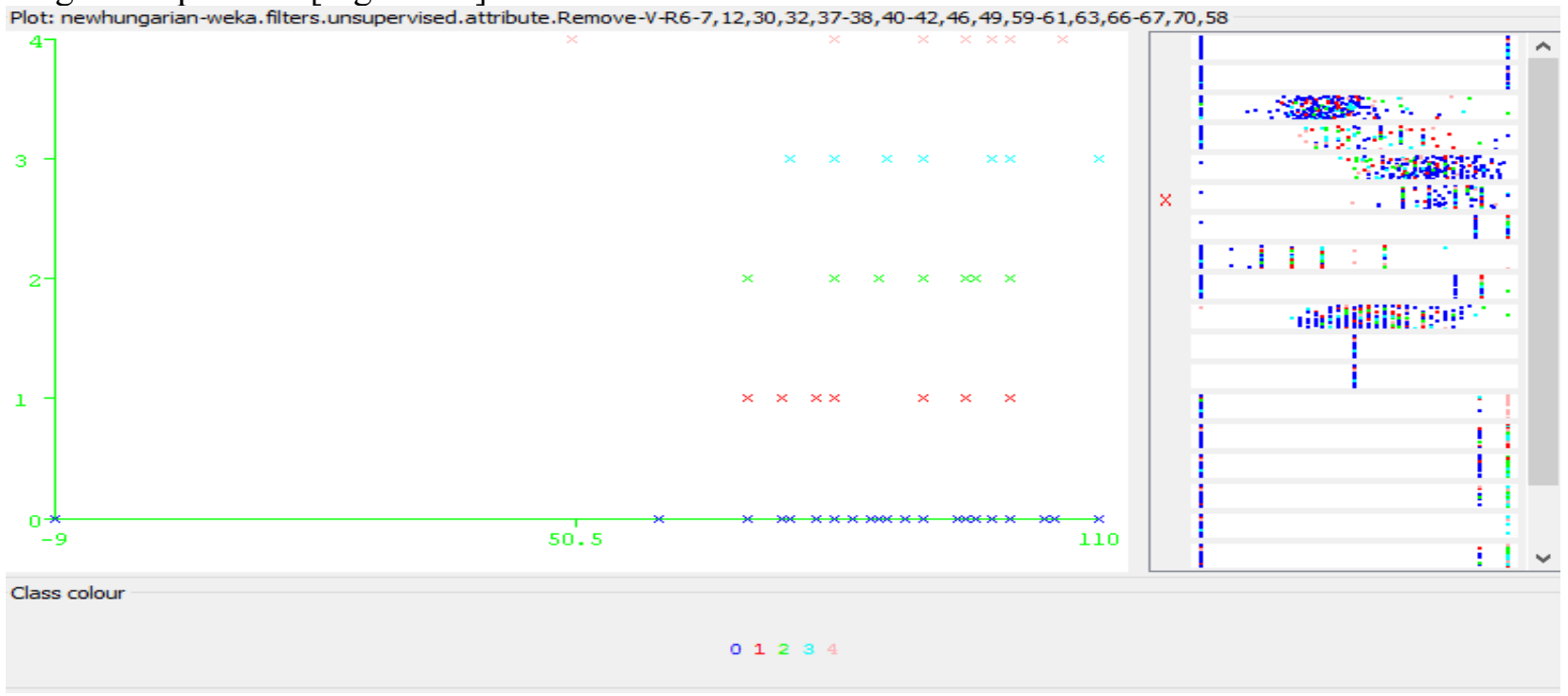

Figure 3: Resting Blood Pressure for Selected Parameter after Reduction 
In the analysis this work demonstrates the appropriate distribution over nominal parameter with height at rest [Figure -4$]$.

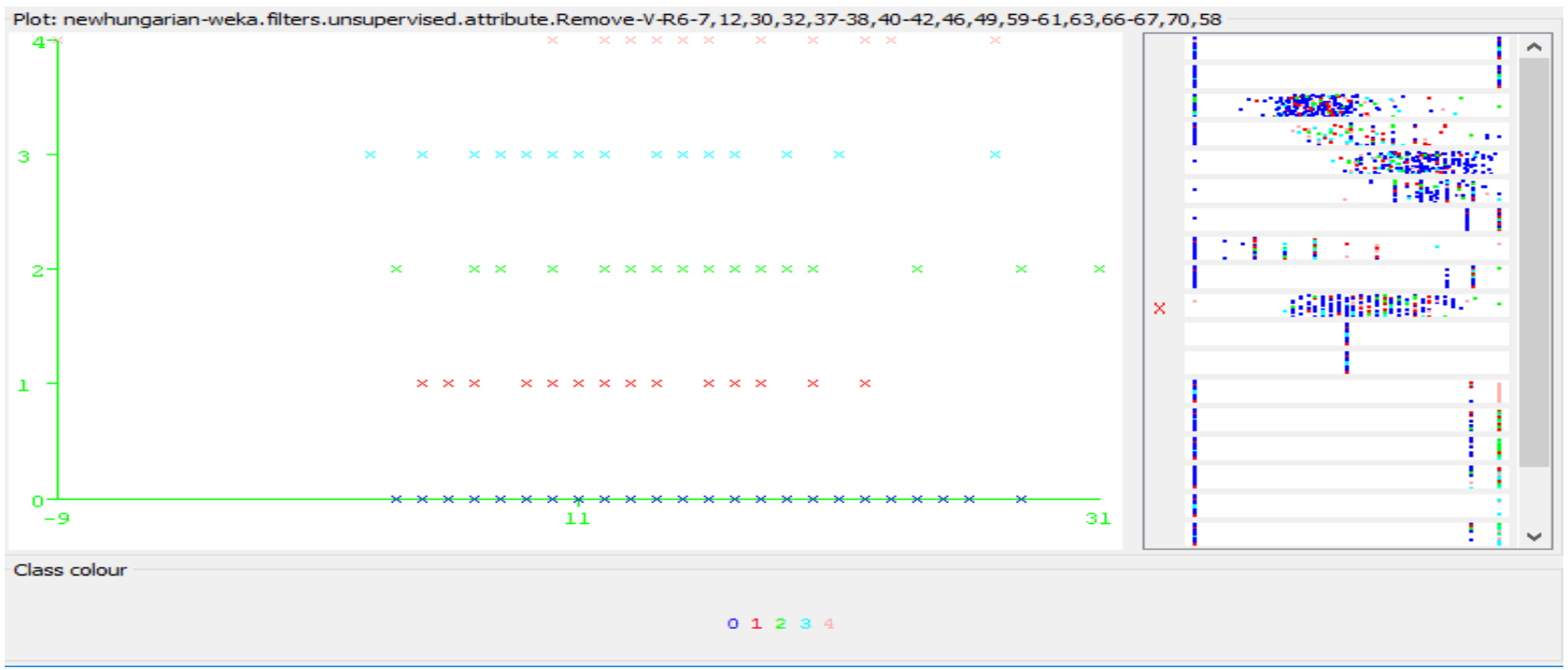

Figure 4: Height At Rest for Selected Parameter after Reduction

In the analysis this work demonstrates the appropriate distribution over nominal parameter with major blood vessel branch [Figure - 5].

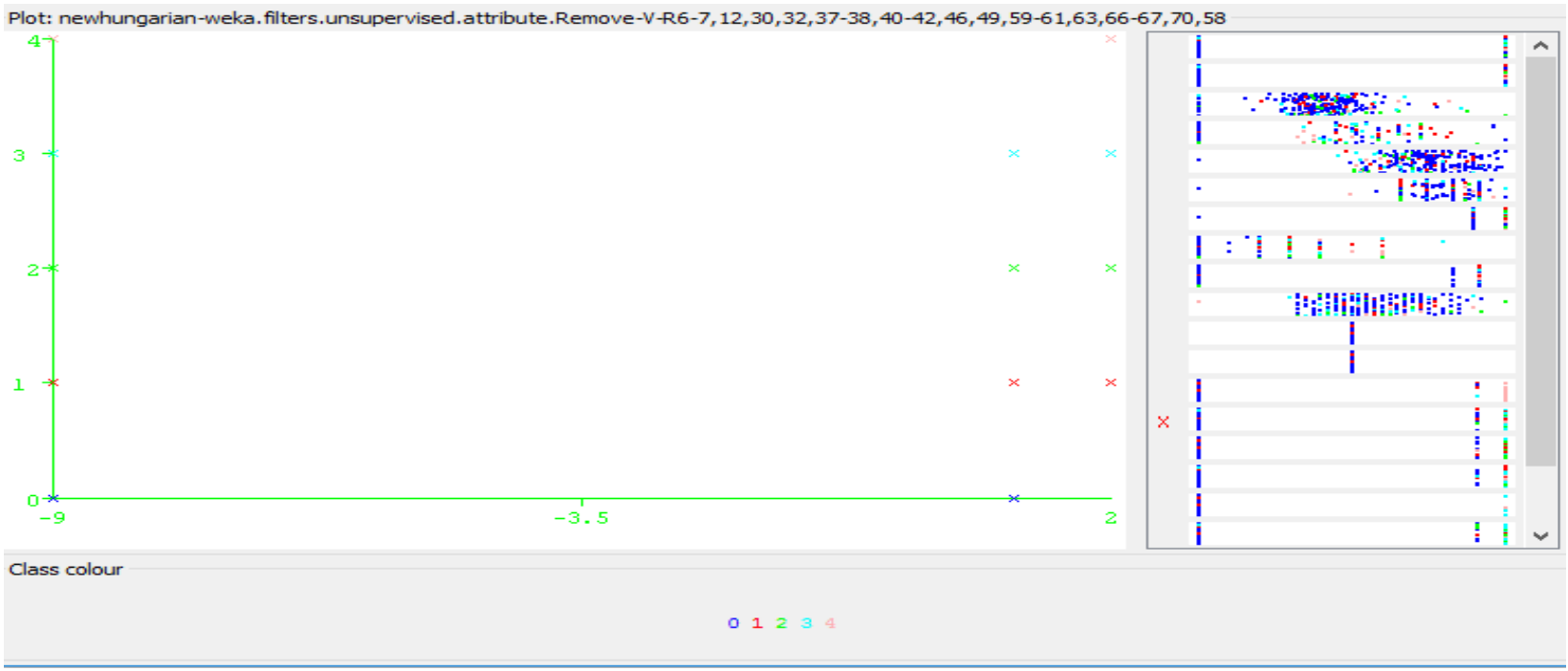

Figure 5: Major Blood Vessel Branch for Selected Parameter after Reduction

\section{IV.CONCLUSION}

The work analyses the current advancements in the space of cardiovascular disorders. The problems identified by the recent advancements as a clear demand for a technique to identify most appropriate set of parameters to be processed during predictive analysis and a demand for finding the optimal neural network setup for predictive analysis. This work demonstrates the optimal genetic algorithm based searching techniques to find the optimal set of attributes for better and timely prediction of the clustering techniques. The constructions of the most appropriate attributes set is been automated for any given dataset. 


\section{REFERENCES}

[1] Asha Gowda Karegowda and M.A. Jayaram, March 6-7, 2009. Cascading GA \& CFS for Feature Subset Selection in Medical Data Mining. International Conference on IEEE International Advance Computing Conference (IACC'09), Thapar University, Patiala, Punjab India.

[2] I. H. Witten, E. Frank. 2005. Data Mining: Practical machine learning tools and techniques. 2nd Edition, Morgan Kaufmann, San Francisco.

[3] J. Han And M. Kamber. 2001. Data Mining: Concepts and Techniques. San Francisco, Morgan Kauffmann Publishers.

[4] D. Michie, D.J. Spiegelhalter, and C.C. Taylor, "Machine Learning, Neural and Statistical Classification", Ellis Horwood Series in Artificial Intelligence, 1994.

[5] J.R. Quinlan, C4.5: Programs for Machine Learning. Morgan Kaufmann, 1993.

[6] Z. Haiyang, "A Short Introduction to Data Mining and Its Applications", IEEE, 2011

[7] D. Goldberg .1989. Genetic Algorithms in Search, Optimization, and Machine learning, Addison Wesley,

[8] Jennifer G. Dy. 2004. Feature Selection for Unsupervised Learning, Journal of Machine Learning, pp845-889.

[9] Manoranjan Dash, Kiseiok Choi, Petr Scheuermann, Huan Liu. 2002. Feature Selection for Clustering - a Filter Solution. In Proceedings of the Second International Conference on Data Mining.

[10] M. Dash 1, H. Liu2. March 1997. Feature Selection for Classification, Intelligent Data Analysis 1 (131-156, www.elsevier.com/locate/ida]

[11] Ron Kohavi, George H. John.1997. Wrappers for feature subset Selection, Artificial Intelligence, Vol. 97, No. 1-2. pp. 273-324.

[12] Shyamala Doraisamy ,Shahram Golzari ,Noris Mohd. Norowi, Md. Nasir B Sulaiman , Nur Izura Udzir. 2008. A Study on Feature Selection and ClassificationTechniques for Automatic Genre Classification of Traditional Malay Music. ismir2008.ismir.net/papers/ISMIR2008 256.pdf(2008).

[13] Mark A. Hall, Correlation-based Feature Selection for Machine Learning, Dept of Computer science, University of Waikato .http://www.cs.waikato.ac.nz/ mhall/thesis.pdf

[14] Y.Saeys, I.Inza, and P. LarrANNaga,. 2007. A review of feature selection techniquesin bioinformatics, Bioinformatics, 23(19),, pp.2507-2517.

[15] M.A.Jayaram, Asha Gowda Karegowda.2007. Integrating Decision Tree and ANN for Categorization of Diabetics Data. International Conference on Computer Aided Engineering, December 13-15, 2007, IIT Madras, Chennai, India.

[16] P. J. Werbos, "Backpropagation Through Time: What It Does and How to Do It", IEEE, 1990

[17] H. Lu, R. Setiono, and H. Liu, "Effective Data Mining Using Neural Networks", IEEE, 1996

[18] Y. Bengio, J. M. Buhmann, M. Embrechts, and J. M. Zurada, "Introduction to the special issue on neural networks for data mining and knowledge discovery," IEEE Trans. Neural Networks, vol. 11, pp. 545-549, 2000.

[19] UCI Machine Learning Repository: http://archive.ics.uci.edu/ml/datasets.html

[20] Volfer Rotz, and Tilman Lange. 2003. Feature Selection in Clustering Problems", In Advances in Neural Information Processing Systems 16. 
About the Authors:

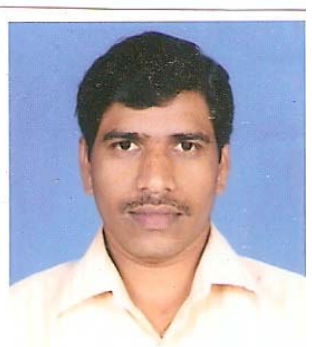

Mr.P.Sambasiva Rao is a Research Scholar in the Department of Computer Science and Engineering, GITAM University, Visakhapatnam, India. He has 11 years of experience in Teaching for Graduate and Post Graduate courses. His current research interests are Data Mining, Software Engineering and Cloud Computing.

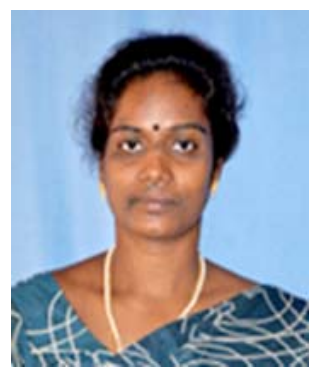

Dr. T.Uma Devi is working as an Associate Professor in GITAM University, Visakhapatnam, India. She did her PhD from Andhra University in 2010. Her research interests include Data Mining, Bio Informatics, Wireless Networks and Information Security. She has been published good number of research publications in reputed international journals and guiding good number of research scholars for Ph.D. She has been the Member for many expert committees, Member of many professional bodies and Resource person for various organizations. 